\title{
Contaminação por Chumbo em Bauru: vigilância sanitária e ações ambientais no período de 2002 a 2007
}

Maria Helena de Abreu, Maria de Lourdes Soares Pereira, Aida Maria Marasco, Mario Ramos de Paula e Silva, Luis Cesar Yoshiori Miyazaki, Analucia Quaglia Serrano Tavares, Niura Aparecida de Moura Ribeiro Padula, Nilce Emy Tomita

Secretaria Municipal de Saúde de Bauru - Departamento de Saúde Coletiva

Endereço: Av. Lisboa Júnior, 266 - Altos da Cidade - Cep 17014-274 - Bauru, SP, Brasil.

email: mariahelenaabreu@bauru.sp.gov.br

\section{RESUMO}

Em 2002, após interdição de empresa metalúrgica pela CETESB (por emissão excessiva de chumbo), comprovou-se plumbemia $10 \mu \mathrm{g} / \mathrm{dl}$ em crianças expostas. Com participação da SES-SP, SMS-Bauru, IAL/SES, CETESB, MS, FUNDACENTRO, FCM-UNICAMP, FMBUNESP, FC-UNESP Bauru, FOB-USP e HRAC-USP, foi realizada investigação epidemiológica em raio de $1 \mathrm{~km}$ da fonte, com entrevistas domiciliares e dosagens de plumbemia, pesquisa de alimentos, água, vegetação e solo. Das 882 coletas de sangue, constatou-se 317 crianças e uma gestante com valores $10 \mu \mathrm{g} / \mathrm{dl}$, que foram avaliadas, acompanhadas e tratadas por equipe multiprofissional. As amostras de água mostraram valores aceitáveis, já a vegetação e os alimentos (leite 
in natura, ovos e hortifrutigranjeiros) mantiveram contaminação de 2002 a 2007, bem como o solo superficial. Com restrição do consumo de alimentos da área, saneamento de residências e raspagem do solo superficial na área habitada, os exames de seguimento mostraram 79\% das crianças com redução de plumbe-

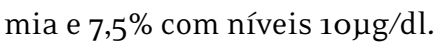

